\title{
Emergency urethroplasty for penile urethral injury in a case of blunt trauma of the penis: challenges and dilemmas during management
}

\author{
Ketan Mehra, Sidhartha Kalra, Dorairajan Lalgudi Narayanan, Manikandan Ramanitharan, Sreerag \\ Sreenivasan
}

Jawaharlal Institute of Postgraduate Medical Education and Research (JIPMER), Puducherry, India

\begin{abstract}
Penile urethral injury may be associated with cavernosal rupture due to distractive force during coitus. Non-coital penile injury due to direct blow to the penis causing penile urethral and cavernosal rupture is rare. Definite management of urethral injury in such cases can be deferred as extent of devitalised tissue can be deceptive in acute conditions.

Key words: Penile injury, Non-coital injury, Urethral injury, Urological trauma
\end{abstract}

\section{Introduction}

Injuries to the penile urethra from blunt external trauma are very rare. Urethral injuries associated with blunt trauma are primarily reported in the context of posterior urethral injuries1. Anterior urethral injuries comprise only $10 \%$ of lower urinary tract injuries, with bulbar urethral injuries accounting for $85 \%$ of them 2 . These are commonly due to straddle injuries arising from a fall from a height or a road traffic accident. Non-iatrogenic penile urethral injuries are associated with $15-37 \%$ of penile fractures 2 . Microvascular injuries in direct penile urethral trauma can cause urethral loss over time, making their management challenging3. We report our experience in managing a patient with penile urethral injury due to blunt external trauma that resulted in extensive penile urethral loss and discuss the challenges faced in the management.

\section{Case presentation}

A 52-year-old male presented to the emergency services following a fall from a height of about 6 feet with direct impact to the penis. At the time of presentation there was blood at the urethral meatus with 'eggplant deformity' of the penis, typically seen in cases of cavernosal rupture associated with penile fractures4. There were no other associated injuries. Ultrasound of the penis showed a 4-cm subcutaneous haematoma but no defect in the tunica albuginea. Retrograde urethrography showed urethral disruption with extravasation of contrast into the corpora cavernosa (Figure 1). After diagnosis of penile urethral injury, the patient was taken for exploration of the injury. Operative findings were a $2-\mathrm{cm}$ loss of penile urethra, a haematoma overlying it and a defect in the adjacent tunica albuginea on the ventral aspect of the corpora cavernosa (Figure 2). After evacuating the haematoma and repairing the tunica albuginea defect, primary end to end anastomosis of the urethra was performed. The urethra was mobilised proximally up to the bulbar urethra and an end to end anastomotic urethroplasty was done over a 16 French Foley catheter with interrupted 4-0 polyglactin sutures. A suprapubic catheter was inserted as urinary diversion. Postoperatively, the patient developed a 3-cm black discoloration of the skin on the ventral aspect of the penis which slowly necrosed within 5 days (Figure 3). Subsequently, the surgical site was explored again and was found to have dehiscence of the urethral anastomosis with $3 \mathrm{~cm}$ of the proximal urethral end sloughed off. After debriding the sloughed urethral ends, the proximal and distal healthy urethral ends were exteriorised separately on the ventral aspect of the penis (Figure 4). The patient recovered and was voiding well from the neomeatus on follow up. Second stage surgery is planned to be performed soon.

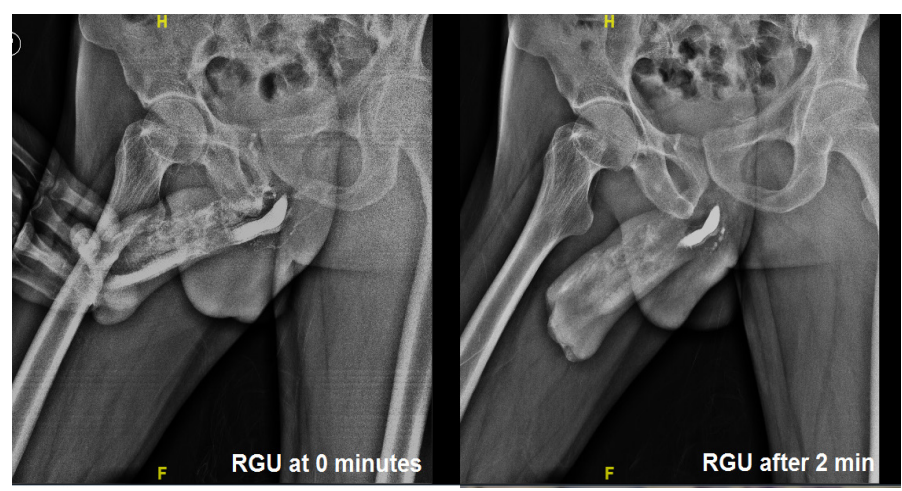

Figure 1. Retrograde Urethrogram (RGU) suggestive of urethral injury and extravasation of the contrast in the cavernosal tissue

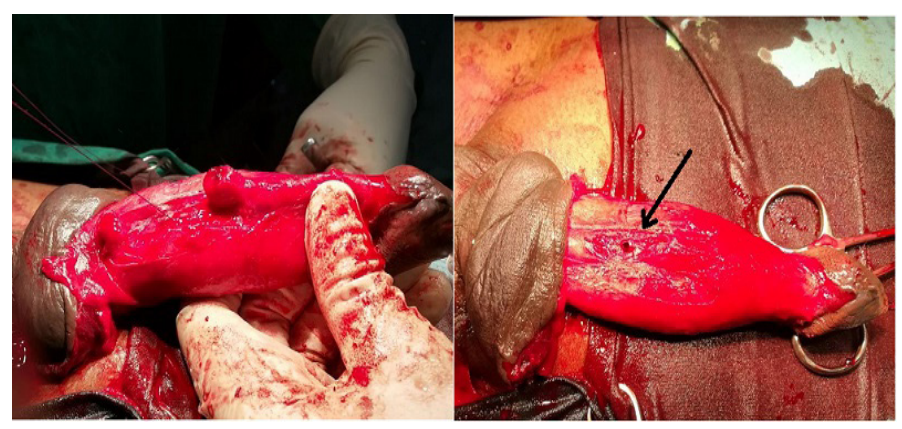

Figure 2. Suggests urethral injury along with defect of $2 \mathrm{~cm}$ and cavernosal injury 


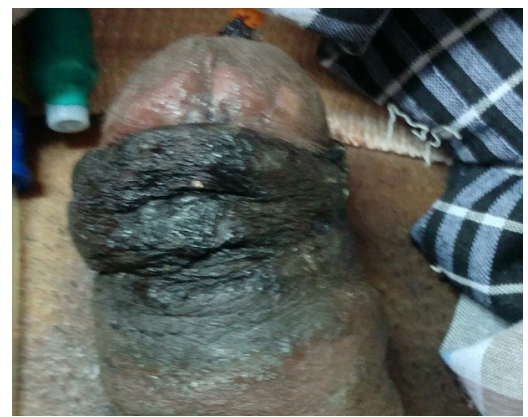

Figure 3. There is blackening of the distal penile skin at Post op day 2.

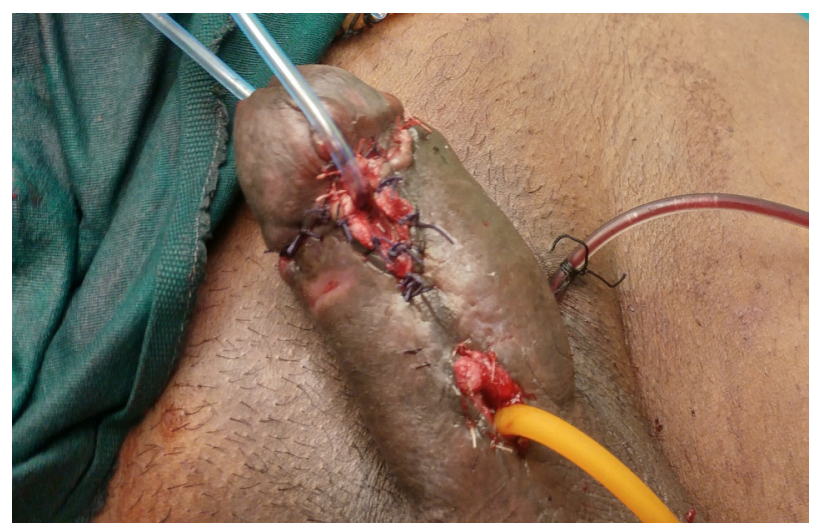

Figure 4. After debridement of the dead skin distal and proximal opening of the urethra was exteriorized

\section{Discussion with literature review}

The bulbar urethra is the most common site of injury to the anterior urethra following blunt injury. Rupture of the corpora cavernosa, commonly known as penile fracture when it occurs during erection, can occur when the engorged penile corpora are forced to buckle and rupture under the pressure during sexual activity. This may be accompanied by urethral injury. Injury to the corporal bodies of the penis by other forms of external trauma is rare due to its secluded location between the thighs and also as it is mobile when it is flaccid. For the same reason, injury to the penile urethra from blunt external trauma is rare5. Urethral trauma was reported in only $3 \%$ of penile trauma cases by Zargooshi6. Blood at the urethral meatus is the cardinal sign and retrograde urethrography is the standard investigation for the evaluation of urethral injury3,7. The treatment of penile urethral injury depends on the type and the mode of injury. Urethral injury associated with penile fracture can be repaired immediately along with tunica albuginea repair8. Owing to its rarity there is a paucity of evidence-based guidelines on the treatment of blunt external trauma causing crush injuries to the corpora cavernosa and the spongy penile urethra.

Cavalcanti et al, studied 77 cases of penile injuries, among which $72(93.5 \%)$ patients had sexual trauma9. Only one $(1.3 \%)$ patient had direct trauma to the flaccid penis as in our case. There were a total of 11 patients with a urethral injury: 8 were partial and 3 were a total laceration. In case of partial injury urethral closure was carried out and in total injury end to end anastomosis was carried out primarily. They reported a good outcome of primary repair except mild chordee of the penis. However, most of the urethral injuries were due to sexual trauma and not crush injury to the penis as in our case.

In a consensus on genitourinary trauma, Morey et al, suggested that after debridement, complete transaction cases can be repaired primarily after adequately mobilising it for tension-free repair10. Partial disruptions can be managed by either placing a urethral catheter alone, suprapubic cystostomy alone, or primary repair.

We opted for primary repair of urethra in our patient in view of the apparently healthy urethral margins at the time of exploration and our ability to bridge the gap without any tension with adequate proximal urethral mobilisation. Postoperatively the patient developed penile skin ischaemia and necrosis, which could possibly be due to local skin trauma aggravated by degloving through circum-coronal incision leading to compromised vascularity. A linear incision over the injury would had been sufficient to reduce the skin loss. We conclude from our case that with spongiosal contusion it is difficult to evaluate the extent of non-viable urethra immediately after injury7. The outcome in our case showed that the condition of the tissues in such scenarios can be deceptive. Exploration by minimal incision and damage control by exteriorising the ruptured urethra with a second look after 48 hours may be the better alternative.

\section{Conclusion}

In cases of blunt injury of the penis, the decision of emergency urethroplasty can be dubious due to deceptive local conditions. Extensive surgery can be deferred in the acute setting. Exploration with damage control surgery may be optimal in such cases. In resource-constrained environments, like in Malawi, initial debridement with exteriorization of the urethra can be safe and allow for definitive management with a specialist team in the future.

\section{References}

1. Rosenstein DI, Alsikafi NF. Diagnosis and classification of urethral injuries. Urol Clin N Am. 2006;33(1):73-85

2. Richter ER, Morey AF. Urethral trauma. In: Wessells HB, McAninch JW, editors. Urological emergencies. A Practical Guide. Totowa, NJ: Humana Press; 2005. p. 57-69.

3. Mundy AR, Andrich DE. Urethral trauma. Part I: Introduction, history, anatomy, pathology, assessment and emergency management. BJU Int. 2011;108(3):310-27.

4. Waseem M, Upadhyay R, Kapoor R, Agyare S. Fracture of the penis: an atypical presentation. Int J Emerg Med. 2013;6(1):32.

5. Kitrey ND, Djakovic N, Gonsalves M, Kuehhas FE, Lumen N, Serafetinidis E. EAU Guidelines on urological trauma. 2016;27-34

6. Zargooshi J. Penile fracture in Kermanshah, Iran: report of 172 cases. J Urol. 2000;164(2):364-6.

7. Chapple C, Barbagli G, Jordan G, Mundy AR, Netto NR, Pansadoro V et al. Consensus statement on urethral trauma. BJU Int. 2004;93:1195.

8. Eke N. Fracture of the penis. Br J Surg. 2002;89(5):555-65.

9. Cavalcanti AG, Krambeck R, Araújo A, Rabelo PH, Carvalho JP, Favorito LA. Management of urethral lesions in penile blunt trauma. Int J Urol. 2006;13(9):1218-20.

10. Morey AF, Metro MJ, Carney KJ, Miller KS, Mc Aninch JW. Consensus on genitourinary trauma: external genitalia. BJU Int. 2004;94(4):507-15. 